\title{
Dealing with the uncertainties of climate engineering: Warnings from a psychological complex problem solving perspective
}

\author{
Dorothee Amelung*, Joachim Funke \\ Department of Psychology, Heidelberg University, Hauptstraße 47-51, 69117 Heidelberg, Germany
}

\section{A R T I C L E I N F O}

\section{Article history:}

Received 16 November 2012

Received in revised form 1 March 2013

Accepted 2 March 2013

Keywords:

Complex problem solving

Geoengineering technology

Decision-making

Uncertainty

Climate politics

\begin{abstract}
A B S T R A C T
Decision-makers in the context of climate politics are confronted with considerable uncertainties due to the complexities inherent in the relevant natural and social systems. Nonetheless, pressure on decision-makers to find solutions to dangerous climate change is rising due to the inertia in the climate system. Considering these pressures, technological options (climate engineering) have been proposed to counteract the effects of climatic change. However, introducing options that bear their own scientific uncertainties means further adding to the complexity of the situation. By adopting the psychological perspective of complex problem solving research, we analyze one frequently neglected source of uncertainty with regard to climate engineering: errors of the political problemsolver in his interaction with the situational demands of complex problems. More specifically, we examine the psychological sources for human error that are common in dealing with the uncertainties implied in this type of problem. We will conclude from the complex problem solving perspective that a consideration of climate engineering in the context of climate change can provide a dangerous illusion of controllability.
\end{abstract}

(c) 2013 Elsevier Ltd. All rights reserved.

\section{Introduction}

Decisions in the context of climate politics are commonly regarded as decisions under uncertainty [1], even more so with the introduction of an additional possible strategy: the intentional technological intervention in the global climate system on a planetary scale (geoengineering or, more adequately, climate engineering, hereafter shortened to $\mathrm{CE}$ ). From a psychological perspective, we can conceive of this decision situation as a complex problem because very generally speaking, complex problems require dealing with (psychological) uncertainty [2]. Therefore, in the present paper, we wish to stress the psychological problem solving perspective: in order to do so we will first give an introduction to the concept of complex problems and how it

\footnotetext{
* Corresponding author. Tel.: +49 6221 547571; fax: +49 547273.

E-mail address: dorothee.amelung@psychologie.uni-heidelberg.de (D. Amelung).
}

applies to the CE situation. We will proceed with the implications for the problem solver. We will put emphasis on explaining human errors and failures in the area of decisions under uncertainty given that this decision type is closely linked to human interaction with complex problems. These errors and failures can be considered in themselves as a new source of uncertainty that adds to the complexity of the situation. We will conclude from the complex problem solving perspective that a consideration of $\mathrm{CE}$ in the context of climate change at best offers an unjustified illusion of controllability.

\section{Why finding a solution to climate change means solving a complex problem}

Having a problem means having a goal (e.g., reducing the impacts of climatic change) while being uncertain about how to reach it. Solving a problem implies a search 
process for means with which to overcome the barrier imposed by the problem. In the case of climate politics, possible means to achieve the goal could be: (a) mitigating $\mathrm{CO}_{2}$ emissions, (b) adapting to the consequences of climatic change, (c) deploying technological options (i.e. CE) or a combination of these. What is the central aspect that imposes barriers on the problem-solver within this context? In order to control the complex environment around them, problem-solvers need to reduce the uncertainties involved in the problem $[2,3]$. These uncertainties stem from certain characteristics of the problem that will be outlined in the following.

From a problem solving perspective, a situation in which a strategy to deal with climate change has to be chosen (e.g., a decision for or against a deployment of $(E)$, can be described as a complex problem. A complex problem is said to occur when the following characteristics of it complicate the finding of a solution due to an enhanced level of uncertainty $[4,5]$ : (a) the number of elements relevant to the solution process is large (complexity) as well as highly interconnected (connectivity), and (b) the system is dynamically changing over time (dynamics). In addition, (c) neither the decision structure nor its dynamics are fully disclosed to the actor (intransparency). Finally, (d) goals are not easily set: in dealing with a complex problem, a decision maker is confronted with a number of different goal facets that have to be weighted and coordinated (polytelic situation).

Let us say that, for instance, a nation state is faced with extreme weather phenomena such as storms or droughts that are attributable to climate change. The severity of these weather events threaten crop yields and thus the food supply, which results in an enhanced pressure on the government to decide on the deployment of a CE technique such as stratospheric aerosols [6]. The government of this state is now faced with a complex problem as we can show by reference to such a problem's five characteristics:

(a) Complexity. The number of items of information that need to be taken into account to come to an adequate solution is extremely large if one does not only include the physical variables (Is this specific technique effective enough to reduce the occurrence of extreme weather events? What are the risks that can be expected?), but also the psychological and social aspects (How will the voters of the government react to such a decision?), the economical aspects (Are the costs of deployment justified when compared to the benefits and risks?), and political or legal aspects (As the effects of this option will be global in extent, how can a consensus be reached with other states? Will other states eventually feel threatened by a deployment?).

(b) Connectivity. CE interacts with an already intensely connected network of variables: not only would such an option influence the already highly interconnected variables of the climate system, such as temperature, precipitation patterns and the ozone layer, it would also interact with, for example, social systems. For instance, the fear of anticipated negative side-effects of a deployment could lead to public mobilization processes in neighboring states which means that even in the (unlikely) absence of such negative side-effects the potential for conflict is expectably high.

(c) Dynamics. CE aims at influencing the intricate future trends of the climate system. In case of a deployment of stratospheric aerosols as described in our exemplifying scenario, the future trend with the targeted intervention would be hard to predict since the aerosols would curb temperature rise but would not alter the amount of $\mathrm{CO}_{2}$ in the atmosphere. However, this is a previously unexperienced scenario.

(d) Intransparency. Not all manifestations of relevant variables and their interconnections can be directly assessed or observed (e.g., many of the climate system's intricacies still are not perfectly understood or only reproduced approximately in climate models) which is why the problem structure is not completely transparent to the problem solver. This also means that, for example, possible unintended consequences of a deployment of stratospheric aerosols could not adequately be determined in advance (e.g., with the help of experimental simulations).

(e) Polytely. As a deployment of stratospheric aerosols would have global effects, yet would involve regional variabilities, there would be winners and losers. Therefore, the goals and interests of other stakeholder groups and nations have to be considered in addition to the individual's goal prioritization process in the face of multiple and partly conflicting goals. In fact, different regional interests with regard to the effects of a CE deployment are one of the major sources of missing consensus.

In summary, these five characteristics of a complex problem imply uncertainties for the problem solver, a barrier that has to be overcome. We conclude, then, that CE within the broader climate politics context can be regarded as a prototype of a complex problem.

\section{Psychological complex problem solving research in the context of climate politics}

If this is the case, can we also conclude that it is useful to draw on psychological complex problem solving research in the context of climate politics? In psychological problem solving research, insights into the question of how individuals deal with complex problems mostly stem from the use of computer-based simulation scenarios [7]. In these scenarios, subjects are in charge of a complex situation for certain periods of time. Such situations can involve managing a company, dealing with a bush fire catastrophe, or finding a solution to the financial crisis in Europe [8]. In order to learn about the effects of different conditions (e.g., degree of complexity; type of semantic embedding; availability of previous knowledge), they are experimentally manipulated and the decision-making process is analyzed afterwards. Insights from this type of research can be relevant for climate politics because important characteristics of the simulation tasks resemble the situation we face in the context of climate politics. 
The complex and dynamic environments in these studies need to be controlled by the participants. This requires them to make decisions in consecutive rounds. In other words, rather than taking one single decision in order to complete the task, the participants need to make a series of interdependent decisions over time. This not only means that they are confronted with uncertainties inherent in the situation and experienced on a psychological level. It also means that they need to remain capable of acting despite of these uncertainties. They are required to act under uncertainty or more specifically, they need to take decisions under uncertainty. All of these aspects are equally relevant in climate politics.

However, one could argue that it is objectionable to generalize from laboratory findings with non-experts to experts in the context of climate politics. One could also argue that, since political decision-makers can (a) rely on expert advice as well as (b) on computer-aided models and (c) are used to taking decisions under uncertainty, they would not be susceptible to the same errors as lay people (e.g., participants in psychological experiments) are.

With regard to (a) expert advice, Philip Tetlock [9] has demonstrated in his long-term study that expert political predictions often are unimpressive and prone to failure, which does not support the assumption of expert advantages under conditions of uncertainty and in complex environments. It becomes clear why one would not assume significant differences between experts and novices as both groups try to control complex dynamic environments that also experts only have very little experience with (e.g., the climate system). This is because one has to (c) take decisions under uncertainty within this type of environment while expertise is characterized by a shift from a high level of experienced uncertainty to a reduced level of experienced uncertainty: "Both experts and novices are susceptible to biases, particularly under highly pressurized conditions [...], or because there simply is not enough information to decide on, or to predict, the outcome in the environment" [2]. Clearly, there is a high level of experienced uncertainty among experts associated with a decision in the context of CE as one alternative in the fight against climate change, since relevant information is, and will likely always be, lacking [10].

So far, we have established that decisions under uncertainty are susceptible to errors regardless of expertise. With regard to (b) it is certainly true that computer-aided models advance our understanding of specific issues. However, the climate models we base our decisions on are not perfect representations of reality and are prone to errors themselves. We will come back to this point in the subsequent sections. We conclude that, as political decisions are commonly made on the basis of certain predictions and strategic forecasts and thus are commonly decisions under uncertainty, errors made by novices in complex and uncertain environments, are comparable to errors made by political experts in similar environments.

\section{Implications of the complex problem solving perspective for the problem solver}

We have argued that a decision in the context of climate politics is a decision under uncertainty. The uncertainties a decision-maker is confronted with in this context result from the characteristics of the problem structure: complexity, connectivity, intransparency, dynamics, and polytely.

What are the consequences for the problem solver, be they a scientist, a politician, or the general public? The different aspects of complex situations have specific demands to the problem solver: (1) complexity requires the reduction of information by means of model building; (2) intransparency requires creating transparency by means of information retrieval; (3) dynamics require the control of systems on the basis of predictions of future trends; (4) polytely requires solving goal conflicts by means of a goal setting process including value decisions and compromises.

We argue that all of these demands amount to the fact that the problem solver has to make decisions under uncertainty because these task characteristics are sources of uncertainty that are then experienced on a psychological level [2] as a "... sense of doubt that blocks or delays action." [11]. This action-blocking sense of doubt is experienced because (1) in the model building process, information has to be reduced, (2) information that is required to create transparency can vary in its relevancy and quality, (3) predictions of future trends are made based on the models as mentioned in (1), and (4) value decisions and compromises between different stakeholder groups that might have been accepted in the face of a goal conflict are not necessarily stable and adequate. Human problem solvers are prone to errors in all four fields: errors in model building, errors in information retrieval, errors in prediction and control, and errors in goal setting.

With the help of an example commonly referred to by scientists in the field of $\mathrm{CE}$, we will establish that a problem in this context features the characteristics complexity, intransparency, dynamics, and polytely. For each of these characteristics, we will exemplify the experienced uncertainties and common errors that result from a human problem solvers' interaction with them. We will discuss each of the four dimensions separately for the reason of clarity. In practice, they can hardly be separated, however, as the demands for the problem solver resulting from the dimensions are intertwined [12].

\subsection{Example of a CE related complex decision}

To illustrate our points, we will consider an example that is commonly referred to by CE scientists: Political decision makers need to decide about the budget that will be spent on CE related research programs. This can be seen as an intervention to gain control over the climate situation. According to Bellamy and colleagues [13], a common line of thought or framing that is found in the peer-reviewed and gray scientific literature on $\mathrm{CE}$ is the following: Mitigation policies are likely to fail to meet the goal of a $2{ }^{\circ} \mathrm{C}$ cap, which will lead to a rise in global average temperature above the designated level. Global warming to such high levels is unprecedented in such a short time frame and therefore potentially dangerous because it could lead to a climate emergency. The implementation of a CE technique, and more specifically one of the so-called Solar Radiation Management (SRM) techniques, is the only presently 
known way to quickly curb the effects of such a climate emergency. This is because SRM techniques aim at blocking incident solar radiation hereby offsetting global warming. Thus, these techniques represent a temporary back-up plan in a future climate emergency scenario that would enable politicians and scientists to work on a more sustainable solution to climate change. Among the more intensively discussed SRM techniques is the stratospheric aerosol option which aims at blocking the radiation by means of tiny sulfur particles that are injected into the higher atmosphere [6]. Given the large time frames still needed to research and develop SRM techniques, a decision for spending money on the development of SRM to have it available in the future needs to be made now. An optimal decision framework from an economic perspective for this situation has been explored in a (simplified) model by Moreno-Cruz \& Keith [14].

\subsection{Connectivity as a characteristic of a CE related complex decision}

A CE deployment would interact with an intensely connected network of variables in the climate system as well as relevant political and social systems. In our example, we focus on the seemingly much simpler decision whether to fund a research and development program of one specific SRM technique (stratospheric aerosols) to have it available as a back-up plan in the future. However, the decision that is made today with regard to research and development is not independent of a future decision for or against deployment as strategic economic deliberations demonstrate [14]. Facing a complex situation means that a range of highly interconnected variables needs to be considered. In taking a decision for allocating parts of the available budget on an SRM research program, our decision maker is faced with the interconnectedness of the available climate strategies mitigation, adaptation and CE (SRM). This is best exemplified by the so-called moral hazard problem, a systemic response comparable to a rebound effect, that refers to the idea that the prospect of having a fast and seemingly simple technological solution like CE available in the future could undermine present mitigation efforts [15] as well as its counterpart (the possibility that this very notion could scare the public into heightened mitigation efforts [6]).

However, the decision maker also needs to take the anticipated interactions of the method he wants to support (e.g., the stratospheric aerosols) with the climate system's variables into account, even if he does not intend to implement this technique at this point in time. This is because it would be a waste to spend limited resources on a technique that could already be ruled out as a potentially effective means to counteract detrimental climate change effects.

\subsubsection{Human error as a result from connectivity}

The task of dealing with the interconnected variables as illustrated in the preceding section transcends the capacity of human memory. Therefore, our decision maker needs to draw on computer models and simulations that are run by climate experts. Apart from the fact that this reliance on outside expertise poses its own challenges regarding effective communication [cf.[16]], there are restrictions set by limited computational power, human ignorance of important factors, or simply a lack of available data, which render the models imperfect. As a result, the human problem solver is likely to be confronted with the uncertainty whether a future targeted intervention with stratospheric aerosols in case of an emergency would be effective enough [cf.[2]], as climate changes are not likely to be entirely reversible with the aerosol technique [17,18], anticipated outcomes are highly dependent on a multitude of input variables such as aerosol size, altitude of injection, or aerosol material $[19,20]$, and anticipated outcomes are likely to be regionally diverse so that, for example, a climate crisis in the tropics could be avoided but not a polar crisis [17,18].

Even without reliance on scientific climate models, the mind of our decision maker obviously is no "blank slate" which means that he has a mental model of his environment, of the complex problem he wants to solve that necessarily reduces information [21]. Among the typical errors human problem solvers face when reducing information to build mental models to deal with many largely interconnected variables, are the ignorance against side effects [22,23], and tipping points [24]. As a result, the decision maker is likely to experience uncertainty with regard to his ability to adequately predict the state of his environment.

Accumulated side effects can significantly disrupt the intended main effects. In this context the term policy resistance refers to the "...tendency for interventions to be defeated by the system's response to the intervention itself." [25] Sterman argues that policy resistance is a common phenomenon due to the boundaries of our mental models. Let us assume that, in our example, the problem solver decides to invest a certain amount of the climate budget into the research and development of the strategy of stratospheric aerosols. The research program includes a field experiment. His intended main effect is having the option available in a future emergency scenario. However, due to coupled processes, one action has rarely only one effect: he has not anticipated the strong reactions of the people who reside near the site of the field experiment. The locals demonstrate and stop the field test. But this is only one outcome in a chain of effects that accumulate in ultimately leading to the decision maker's resignation from his position because he has lost the confidence of his voters. His successor does not consider CE again. This example shows how unanticipated side effects can deeply disrupt the intended main effect.

Complex dynamic systems, ranging from financial markets to ecosystems and the climate, can have tipping points at which a sudden shift to a contrasting dynamical regime may occur [26]. The prediction of such tipping points is very difficult, even with complex computer-aided models. Therefore, the search for early warning signals is essential which is why the endeavor to find indicators for a system that approaches a critical threshold becomes increasingly recognized [27]. Potential tipping points complicate our political decision maker's ability to assess the likelihood as well as the severity of a future emergency scenario for which he wants to prepare. 


\subsection{Intransparency as a characteristic of a CE related complex} decision

Our decision maker is confronted with the fact that not all variables, which are relevant to his decision are known to him. Furthermore, the manifestations of the known variables are not necessarily established, or only by approximation. Latent variables often are estimated on the basis of inferences from observations. This is certainly true for the climate system. Climate scientists have to historically reconstruct temperature from tree rings or glacier geometry [28] or infer the permafrost's sensitivity to future global warming from past historical reactions to temperature changes by analyzing relict ground ice [29]. But intransparency can also arise from the fact that a decision maker has to rely on outside expertise: not everything a problem solver can possibly know of is communicated to him by scientists or other experts, not due to intentional concealment but because time is limited and complex information needs to be condensed in some way (on the issue of adequately communicating climate related issues to political decisionmakers, see Ref. [16]). Furthermore, there might be intransparency with regard to the preferences of different stakeholder groups, among them our decision maker's voters.

\subsubsection{Human error as a result of intransparency}

The human reaction to intransparency is experienced (psychological) uncertainty, which in turn provokes fear (and other negative emotions) and which usually leads to a more intensive information search [30]. Thus, our emotional state serves as a signal to guide our attention to problems and to regulate our behavior answering these problems. As we retrieve more information about the situation, thus reducing the experienced uncertainty, we should gain confidence and feel better. However, we have established that the connectivity and complexity of the situation necessarily requires the reduction of information to form an adequate model (see Section 4.2.1). This means that the identification of relevant information as opposed to irrelevant information is a crucial aspect of a successful interaction with complex systems [31,32]. For example, it will be less relevant for our decision maker to know if the mayor of a small town in a neighboring country supports his plans on funding SRM research, than to know the position of his country's tax payers. As a consequence, our decision maker is confronted with a considerable amount of uncertainty with regard to the relevancy and completeness of the information he bases his decision on.

However, a piece of information that is relevant for the decision is not necessarily reliable either because it contains errors or it is based on erroneous assumptions. For example, the Special Report on Emission Scenarios (SERS) of the IPCC specifically deals with four different scenario groups developed by Nakicenovic and Swart [33]. These emission scenarios are based on different assumptions concerning the demographic, societal, economic, and technological changes that the world might face in the future. Climate Change Scenarios based on these four different sets of assumptions necessarily yield different prognoses [34]. Some of these assumptions and their corresponding scenarios will necessarily prove to be erroneous. However, this is the best available data our decision maker can get at this point in time.

In climate change, the issue of the time frame or quantity of information is of great importance when assessing the reliability of information: Is the time period long enough that we consider to differentiate the signal (anthropogenic climate change or the effects of an SRM implementation) from the noise (natural variations in the global climate)? For example, if our decision maker decides to test the stratospheric aerosols in the field to assess the potential positive effects on temperature as well as the risks before full-scale implementation, he would need to separate the effects from natural fluctuations as well. Therefore, with such a test, a trade-off decision would be needed between the duration of it, the magnitude of it and the uncertainty of any estimated climate response: "Accurate estimates at a local scale would require greater time or larger forcing”. If our decision maker wants to restrict the magnitude of the test (for example, because with larger forcings, the line between field test and full implementation becomes blurry, possibly also threatening his relations with neighboring states) he would want to plan many years ahead: “...accurate estimates could require several decades or longer" [35].

In summary, our decision maker needs to assess whether the information he bases his decisions on is sufficient, relevant and of good enough quality or if additional or different information has to be gathered, all of which adds to his experienced uncertainty and the possibility for failure.

\subsection{Dynamics as a characteristic of a CE related complex decision}

Our decision maker needs to deal with an environment that constantly changes with and without his interference. The inertia in the climate system is responsible for long time delays, contributing to the fact that these changes do not occur in a rapid manner. This means that neither the decision makers nor those who will be affected by the decisions are constants in our equation: Our political decision maker who decides the direction we take today in climate politics (e.g., over the funding of research programs on stratospheric aerosols) is not necessarily the one who will be affected by this direction, nor the one who is going to decide over the strategies in the future (e.g., over a possible deployment of the stratospheric aerosol method in case of a climate emergency). Thus, the dynamics of the situation give rise to questions concerning, for example, intergenerational justice and the question what the preferences of future generations might look like [36-38].

\subsubsection{Human error as a result of dynamics}

Complex dynamic systems require making predictions about future events to exercise adequate control over them. Based on projections of the climate characteristics we can expect in the future, our problem solver takes decisions to influence the situation. Thus, these predictions affect his ability to control. Furthermore, to adequately predict changes of the environment with and without interventions, he needs to draw on his mental model to support his decisions, which necessarily has to reduce information (see Section 4.2.1). 
Because, as we have already outlined, both mental and computer-aided models are not reality and have their shortcomings, the problem solver needs to assess the validity of the predictions based on these models. This is especially true given the long time perspectives in the climate change problem as with larger time frames, the vagueness of predictions increases [39]. Coming back to the example of an SRM field test, if our decision maker decides to carry it out only for a short duration, effects would need to be extrapolated from the effects found during the time frame of the test, yielding significant uncertainties [35]. Thus, the uncertainties that are associated with the climate models he bases his predictions on make it more difficult to control the complex system. More specifically, difficulties as well as errors in prediction represent a source of uncertainty that impedes adequate control.

Where do these difficulties stem from? Regarding his mental model, our human problem solver will have the general tendency to base predictions on simplified linear models that face difficulties when dealing with nonlinearities, cyclic processes, long time delays, and stock and flow principles [4,40-42]. The dynamics of a complex system require learning to improve predictions [43]. It is possible for the human mind to learn to effectively control complex environments $[44,45]$. However, certain preconditions have to be met to enable adequate learning: Learning requires feedback $[21,46]$ while frequent feedback in fast consecutive cycles (with short decision delays) is better suited than less rapid and less frequent feedback response, which is why more frequent policy strategy interventions to improve learning in the context of climate politics have been suggested [47]. However, with climate change, there are no fast feedback responses. Therefore, one needs to rely on simulations.

Of course, feedback can also vary in its quality [22]. This is similar to the issue of the quality of information that we base our decisions on and to the intransparency dimension of a complex problem: as the feedback we observe in the environment often is ambiguous and intransparent, we have to infer from these observations the underlying variables: For example, if our decision maker, after giving funds to his SRM research program, observes that the companies in his region are not meeting their $\mathrm{CO}_{2}$ emissions targets anymore, he might attribute this failure to their managers' reduced motivation to do so because of them relying on the prospect of a climate emergency insurance option, even if the reason might lie elsewhere. For example, the companies' managements might have been waiting for the upcoming annual United Nations Framework on Climate Change meeting's negotiation results with regard to longterm emission targets.

\subsection{Polytely as a characteristic of a CE related complex decision}

Our decision maker is confronted with several goals: he wants to find a solution to climate change in the short and in the long run, he wants to reduce costs, he wants to stay on peaceful terms with neighboring states, and be re-elected at the end of his term of office. All of these goals can be further subdivided into subgoals, for example "finding a solution to climate change" can mean a multitude of things: working with other countries on global treaties to reduce emissions, taking part in carbon trading, promoting climate programs to change the behavior of citizens, reducing the costs of climate damages in the long run, preparing for a possible climate emergency in the future etc. The decision for allocating funds to an SRM research program could be expedient to prepare for a possible climate emergency in the future but it might be conflicting with regard to his reelection or with his behavior change programs (as the notion of an "insurance" against dangerous climate change effects could undermine people's motivation to change their behavior to reduce emissions). The polytelic nature of this situation necessitates setting up priorities and balancing conflicting values and goals. Therefore, in a first step, goals need to be identified (this can be confusing enough for the individual as values have to be prioritized in the face of a hierarchy of numerous goals on different levels of abstraction [48]). However, as soon as our decision maker has identified his own goals, the latter still have to be negotiated with other affected individuals or groups in a second step. Concerning this large-scale emergent technology, what level of risk does a society as a whole wish to accept when balanced against the risks of climate change [49]? Are the stratospheric aerosols an acceptable method, even in case of an emergency, as they are likely to introduce new risks to the environment, for example ozone depletion [50]? Can CE be brought into accordance with a nation's values as well as its cultural and natural belief systems, is it morally justifiable [51]?

\subsubsection{Human error as a result of polytely}

Goals can be shifting in the light of new information or because the conditions in the environment have changed, for example, the preferences of stakeholders. However, this adds to the experienced uncertainty of a political decision maker with regard to his ability to predict and control his environment [cf.[2]] since the stability of any compromise within his nation and between nations largely depends on the stability of the stakeholder groups' interests and goals. Psychological research with complex dynamic systems has shown that people are more successful in the long-term control of these systems with an open-minded learning attitude: the pursuit of a non-specific goal such as to learn as much as possible about the system helps provide the decision maker with the flexibility needed to cope with changing demands of the system and thus changing goals [52-54]. Thus, a more specific goal such as the preparation for a climate emergency does not necessarily allow for this flexibility when the decision maker focuses on it.

The goals of a decision maker largely depend on the mental model he has of the problem: if he views the climate change problem as a risk management issue as opposed to an economic efficiency issue [49], his goals are likely to shift accordingly. This highlights how the different characteristics of a complex problem relate to each other: The connectivity, intransparency, and dynamics of the situation impede the building of an adequate mental model which in turn influences the goal setting process. This also underlines the importance for a decision maker to constantly update his mental model on the basis of new 
information and feedback hereby being open for the possibility to reframe the entire problem rather than to simply integrate new knowledge into the existing model. This type of learning which implies the open-mindedness to challenge existing problem framings, is emphasized by Sterman [21] as an important way of dealing with complex systems. He argues that this type of learning requires the use of simulations for decision makers as well as training of decision makers in scientific reasoning skills.

In addition to this, an open learning attitude can be promoted by the integration of different perspectives. This can apply to the integration of the perspectives of multiple scientific disciplines or the integration of different stakeholders' perspectives. It certainly is essential that the complexity of CE research is dealt with in terms of multiple scientific disciplines to allow for an evaluation of the potential benefits, the risks and uncertainties of CE according to the principle of multiperspectivity $[55,56]$. This is necessary because adopting a complex system's perspective we argue that single perspectives often are too fragmented to adequately understand the intricacies of a system. Moreover, simply aggregating the different perspectives does not necessarily lead to a correct understanding of the system [57]. With regard to the goal negotiation process between stakeholders, a participatory approach involving important stakeholders seems to be appropriate because next to the fact that multiple perspectives likely converge to more appropriate solution proposals, those solutions arising from a transparent participatory process might also be more acceptable to a broader community than single-perspective solutions [58-63].

\section{Discussion}

By adopting the complex problem solving perspective, we were able to identify and systematize the theoretically relevant uncertainties together with common areas of failure that arise from the interaction with the characteristics of a CE related political problem. More specifically, we have argued that human problem solvers face difficulties in model building, retrieving the right amount of relevant items of reliable information, predicting future trends, as well as selecting goals, all of which are basic prerequisites to controlling a complex environment. Climate scientists and experts in CE related fields have argued before that human error in dealing with complex systems should be regarded as one important non-technical risk factor in the emergence of CE [64]. Psychological research in complex problem solving further substantiates this notion because by human errors in model building, information search, prediction, and goal setting, uncertainties are introduced into an adequate decision-making process regarding $\mathrm{CE}$ technology.

However, does this mean that, from a psychological complex problem-solving point of view, the risk of human error outweighs potential benefits of CE? Might there be any hope to overcome the different sources of error and failure in complex problem solving and in decision-making under uncertainty, respectively? The uncertainties we are faced with in our climate models and thus also in the future scenarios upon which political decisions are based, are continuously reduced, for example, with the help of better resolutions, enhanced computational power, or new insights into important factors of influence. However, they are unlikely to be ever completely resolved and new uncertainties might emerge as our understanding of the relevant systems is advanced.

Is it hybris, then, to think humans could safely intervene in the climate system, turning it to their advantage? We have established that learning is the only way of coming to terms with the uncertainty in the management of complex dynamic systems. Therefore, as an important precondition for any problem solver to make effective decisions in the context of $C E$ is an awareness, an active scrutinizing and constant updating of his mental model of the problem structure. Closely linked to this is the need for effective communication strategies between scientists, political decision makers as well as other stakeholders that involve simulation techniques and mapping tools [16], and an open-minded attitude with the true willingness to learn on all sides.

Moreover, to enable learning, goals as well as their underlying models should not be too narrowly defined: framing the issue of climate change around catastrophic scenarios, therefore focusing on the goal of climate emergency preparation should not prevent a decision maker from exploring and learning about other options such as carbon capture and storage or adaptation strategies. A focus on too narrowly defined goals could lead to premature (intellectual) lock-in to any specific technology [cf.[65]].

However, in the CE context, we are faced with multiple situational characteristics that hinder effective learning: decade-long time delays do not allow us to obtain immediate feedback from our actions in fast learning cycles, intransparent processes, and process couplings hinder the unambiguous attribution of cause to effect, ethical considerations as well as the globality of effects make real life experimentation impossible and reliance on imperfect models a necessity. Under these difficult learning conditions, aspirations to adequately predict and control a system, must be exaggerated. However, CE technology specifically aims at controlling a system.

Members of the scientific community have, of course, acknowledged the risks and uncertainties associated with $\mathrm{CE}$ and have fundamentally challenged the idea of trying to interfere with the global climate system by technological means [64]. However, common justifications of pursuing the idea despite all objections involve the argument that the overall goal of CE is not the control of the climate system (as it is acknowledged that this is not possible) but rather that CE might be the lesser evil compared to a future of catastrophic climate change effects and that therefore future generations need to be provided with the option of it [66]. The superficial attractiveness of this argument has already been challenged from an ethical point of view [67]. The complex problem solving perspective adds to these reservations by the following rationale: Even if the case for $\mathrm{CE}$ as a long-term strategy of controlling the climate system is not made, by adopting a mental model following these arguments, the impression is made that the climate system can be controlled at least in the short term until more sustainable solutions have been achieved, for example, by mitigation strategies. This in turn enhances the perceived controllability of the system, at the same time reducing 
psychological uncertainty. We argue that this perceived controllability due to a simplified mental model of the situation (along the lines of "if the worst case happens, we will have a plan b available") might have a reassuring effect on political problem solvers, but is illusionary.

The present article has outlined the reasons for our claim: Let us assume that political problem solvers adopt an open learning attitude and perfectly communicate with the experts they rely on, thus having an updated mental model of the problem structure at their disposal, allowing them to (a) base their decisions on the best available predictions and (b) to set adequate goals and achieve stable compromises with stakeholders. Even under these idealized conditions, we are still faced with the so-called "unknown unknowns" $[68,69]$ : one unforeseen process can significantly disrupt all well-intentioned actions. However, our analysis of the characteristics of a CE related policy problem has shown that erroneous decisions due to inaccurate information, mental models and/or goals are not the exception but can be expected and idealized conditions can therefore not be assumed. Moreover, as our ability to learn to control the complex climate system is dramatically reduced by its inherent characteristics, the complex problem solving perspective severely challenges the illusory assumption of CE being a justifiable control strategy even in the short run and in the case of a climate emergency.

\section{Conclusion}

The present article presents human errors in the interaction with a complex problem of taking uncertain policy decisions with regard to CE technology. By such an adoption of the complex problem solving perspective, these errors can be systematized and practical implications for decision-making can be derived. However, as we have established, dealing with complex dynamic systems requires learning, which is severely complicated by the characteristics of the climate system. Under these conditions, control is likely to be corrupted by the limitations of the human mind. Thus, the psychological complex problem solving perspective calls for a cautious approach to arguments that frame CE as an option of temporary emergency control because such a control is illusionary.

\section{Acknowledgements}

This research was funded by a grant of the Marsilius Kolleg from Heidelberg University. We gratefully thank the members of our Marsilius group The Global Governance of Climate Engineering for fruitful discussions as well as Sandra Boegelein, Melanie Bräunche, Andreas Fischer, Helen Fischer and Stephanie Uther for valuable comments.

\section{References}

[1] Betz G. Underdetermination, model-ensembles and surprises: on the epistemology of scenario-analysis in climatology. Journal for General Philosophy of Science 2009;40:3-21.

[2] Osman M. Controlling uncertainty: a review of human behavior in complex dynamic environments. Psychological Bulletin 2010;136: 65-86.
[3] Aarts N, van Woerkum C. Dealing with uncertainty in solving complex problems. In: Leeuwis C, Pyburn R, editors. Wheelbarrows full of frogs: social learning in rural resource management. Assen, NL: Koninklijke Van Gorcum; 2002. p. 421-36.

[4] Dörner D. The logic of failure. Recognizing and avoiding error in complex situations. New York: Basic Books; 1997.

[5] Funke J. Complex problem solving: a case for complex cognition? Cognitive Processing 2010;11:133-42.

[6] The Royal Society. Geoengineering the climate. Science, governance and uncertainty. London: The Royal Society; 2009.

[7] Fischer A, Greiff S, Funke J. The process of solving complex problems. The Journal of Problem Solving 2012;4(1):19-42.

[8] Frensch PA, Funke J. Complex problem solving: the European perspective. Hillsdale, NJ: Lawrence Erlbaum Associates; 1995.

[9] Tetlock P. Expert political judgement. How good is it? How can we know?. Princeton: Princeton University Press; 2005.

[10] Collins M. Ensembles and probabilities: a new era in the prediction of climate change. Philosophical Transactions of the Royal Society A 2007;365:1957-70. http://dx.doi.org/10.1098/rsta.2007.2068.

[11] Lipshitz R, Strauss O. Coping with uncertainty: a naturalistic decision-making analysis. Organizational Behavior and Human Decision Processes 1997;69:149-63.

[12] Dörner D. Diagnostik der operativen Intelligenz [[Assessment of operative intelligence]]. Diagnostica 1986;32(4):290-308.

[13] Bellamy R, Chilvers J, Vaughan NE, Lenton TM. A review of climate geoengineering appraisals. Wiley Interdisciplinary Reviews: Climate Change 2012;3(6):597-615. http://dx.doi.org/10.1002/wcc.197.

[14] Moreno-Cruz JB, Keith DW. Climate policy under uncertainty: a case for solar geoengineering. Climatic Change 2012. http://dx.doi.org/ 10.1007/s10584-012-0487-4.

[15] Davies GT. Geoengineering: a critique. Climate Law 2010;1:429-41.

[16] Sterman JD. Communicating climate change risks in a skeptical world. Climatic Change 2011;108:811-26. http://dx.doi.org/ 10.1007/s10584-011-0189-3.

[17] Matthews HD, Caldera K. Transient climate-carbon simulations of planetary geoengineering. PNAS 2007;104(24):9949-54. http:// dx.doi.org/10.1073/pnas.0700419104.

[18] McCusker K, Battisti DS, Bitz CM. The climate response to stratospheric sulfate injections and implications for addressing climate emergencies. Journal of Climate 2012;25:3096-116. http:// dx.doi.org/10.1175/JCLI-D-11-00183.1.

[19] Kravitz B, Robock A, Shindell DT, Miller MA. Sensitivity of stratospheric geoengineering with black carbon to aerosol size and altitude of injection. Journal of Geophysical Research: Atmospheres 2012;117(D09203):1-22. http://dx.doi.org/10.1029/2011JD017341.

[20] Pope FD, Braesicke P, Grainger RG, Kalberer M, Watson IM Davidson PJ, et al. Stratospheric aerosol particles and solar-radiation management. Nature Climate Change 2012;2:713-9. http:// dx.doi.org/10.1038/nclimate1528.

[21] Sterman JD. Learning in and about complex systems. System Dynamics Review 1994;10(2-3):291-330.

[22] Brehmer B. Dynamic decision making: human control of complex systems. Acta Psychologica 1992;81:211-41.

[23] Dörner D, Schaub H. Errors in planning and decision-making and the nature of human information processing. Applied Psychology 1994;43(4):433-53.

[24] Thompson JMT, Sieber J. Predicting climate tipping points. In: Launder B, Thompson JMT, editors. Geo-engineering climate change: environmental necessity or Pandora's box? Cambridge: Cambridge University Press; 2010. p. 50-83.

[25] Sterman JD. Learning from evidence in a complex world. American Journal of Public Health 2006;96:505-14.

[26] Bramson AL. Formal measures of dynamical properties: tipping points. AAAI Technical Report 2009;FS-09(3):2-11. Available at: http://www.aaai.org/ocs/index.php/FSS/FSS09/paper/viewFile/853/ 1228.

[27] Lenton TM, Held H, Kriegler E, Hall JW, Lucht W, Rahmstorf S, et al. Tipping elements in the earth's climate system. PNAS 2008;105: 1786-93.

[28] Oerlemans J. Extracting a climate signal from 169 glacier records. Science 2005;308(5722):675-7. http://dx.doi.org/10.1126/science. 1107046.

[29] Froese DG, Westgate JA, Reyes AV, Enkin RJ, Preece SJ. Ancient permafrost and a future, warmer Arctic. Science 2008;321(5896): 1648. http://dx.doi.org/10.1126/science.1157525.

[30] Spering M, Wagener D, Funke J. The role of emotion in complex problem-solving. Cognition and Emotion 2005;19:1252-61.

[31] Gonzalez C, Lebiere C. Instance-based cognitive models of decision making. In: Zizzo D, Courakis A, editors. Transfer of knowledge in 
economic decision making. New York: Palgrave McMillan; 2005. p. $148-65$.

[32] Halford GS, Wilson WH, Phillips S. Processing capacity defined by relational complexity: implications for comparative, developmental and cognitive psychology. Behavioral and Brain Sciences 1998;21: 803-65.

[33] Nakicenovic N, Swart R. Emissions scenarios: special report of working group III of the intergovermental panel on climate change. Cambridge: Cambridge University Press; 2000.

[34] Intergovernmental Panel on Climate Change. Summary for policymakers. In: Solomon S, Oin D, Manning M, Chen Z, Marquis M, Averyt KB, et al., editors. Climate change 2007: the physical science basis. Contribution of working group I to the fourth assessment report of the intergovernmental panel on climate change. Cambridge, New York: Cambridge University Press; 2007.

[35] MacMynowski DG, Keith DW, Caldeira K, Shin H-J. Can we test geoengineering? Energy \& Environmental Science 2011;4:5044-52.

[36] Goeschl T, Heyen D, Moreno-Cruz J. The intergenerational transfer of solar radiation management capabilities and atmospheric carbon stocks. Environmental and resource economics, (in press).

[37] Underdal A. Complexity and challenges of long-term environmental governance. Global Environmental Change 2010;20:386-93.

[38] Goes M, Tuana N, Keller K. The economics (or lack thereof) of aerosol geoengineering. Climatic Change 2011;109(3-4):719-44.

[39] Sarewitz D, Pielke R. Prediction in science and policy. Technology in Society 1999;21(2):121-33.

[40] Brehmer B, Kuylenstierna J, Liljergren JE. Effects of function form and cue validity on the subjects' hypotheses in probabilistic inference tasks. Organizational Behavior and Human Performance 1974; $11: 338-54$.

[41] Sterman JD, Sweeney LB. Understanding public complacency about climate change: adults' mental models of climate change violate conservation of matter. Climatic Change 2007;80(3-4): 213-38.

[42] Brehmer B, Allard R. Real-time dynamic decision making. Effects of task complexity and feedback delays. In: Rasmussen J, Brehmer B, Leplat J, editors. Distributed decision making: cognitive models for cooperative work. Chichester: Wiley; 1991. p. 319-34.

[43] Gonzalez C, Lerch JF, Lebiere C. Instance-based learning in dynamic decision-making. Cognitive Science 2003;27:591-635.

[44] Martin MK, Gonzalez C, Lebiere C. Learning to make decisions in dynamic environments: ACT-R plays the beer game. Department of Social and Decision Sciences. paper 84, http://repository.cmu.edu/ sds/84; 2004

[45] Busemeyer JR. International encyclopedia of the social and behavioral sciences: methodology. Mathematics and computer science. Amsterdam: Pergamon; 1999.

[46] Gonzalez C. Decision support for real-time, dynamic decisionmaking tasks. Organizational Behavior and Human Decision Processes 2005;96:142-54.

[47] Dutt V, Gonzalez C. Human perceptions of climate change. Department of Social and Decision Sciences. paper 79, http://repository. cmu.edu/sds/79; 2008.

[48] Austin JT, Vancouver JB. Goal constructs in psychology: structure, process, and content. Psychological Bulletin 1996;120:338-75.

[49] Kousky K, Cooke RM. The value of information in a risk management approach to climate change. In: Laxminarayan R, Macauley MK, editors. The value of information. Methodological frontiers and new applications in environment and health. Dordrecht: Springer; 2012. p. 19-43. http://dx.doi.org/10.1007/978-94-007-4839-2_2.

[50] Tilmes S, Muller R, Salawitch R. The sensitivity of polar ozone depletion to proposed geoengineering schemes. Science 2008; 320(5880):1201-4. http://dx.doi.org/10.1126/science.1153966.
[51] Hale B, Dilling L. Geoengineering, ocean fertilization, and the problem of permissible pollution. Science, Technology, and Human Values 2010;36(2):190-212.

[52] Osman M. Controlling uncertainty. Decision making and learning in complex worlds. Chichester: Wiley; 2010.

[53] Burns BD, Vollmeyer R. Goal specificity effects on hypothesis testing in problem solving. The Quarterly Journal of Experimental Psychology Section A: Human Experimental Psychology 2002;55(1): 241-61.

[54] Osman M, Heyes C. Practice doesn't always make perfect: goal induced decrements in the accuracy of action-and observationbased problem solving. In: Proceedings of the twenty-seventh annual meeting of the Cognitive Science Society. Mahwah, NJ: Erlbaum; 2005. p. 1690-5.

[55] Carlsen H, Dreborg KH, Godman M, Hansson SO, Johansson L, Wilkman-Svahn P. Assessing socially disruptive technological change. Technology in Society 2010;32(3):209-18.

[56] Wiman BLB. Implications of environmental complexity for science and policy: contributions from systems theory. Global Environmental Change 1991;1:235-47.

[57] Bagheri E, Ghorbani AA. Astrolabe: a collaborative multiperspective goal-oriented risk analysis methodology. IEEE Transactions on Systems, Man, and Cybernetics. Part A: Systems and Humans 2009; 39:66-85.

[58] Sikka T. A critical theory of technology applied to the public discussion of geoengineering. Technology in Society 2012;34(2):109-17.

[59] Renn O, Brachatzek N, Hiller S. Climate engineering. Risikowahrnehmung, gesellschaftliche Risikodiskurse und Optionen der Öffentlichkeitsbeteiligung. Sondierungsstudie für das Bundesministerium für Bildung und Forschung [Climate Engineering. Risk perception, societal risk discourses and strategies of public participation. Exploratory study for the German Ministry of Education and Research]. Stuttgart: DIALOGIK; 2011.

[60] Corner A, Pidgeon N. Geoengineering the climate: the social and ethical implications. Environment: Science and Policy for Sustainable Development 2010;52:24-37.

[61] Klinke A, Renn O. A new approach to risk evaluation and management: risk-based, precaution-based, and discourse-based strategies. Risk Analysis 2002;22:1071-94

[62] Webler T. The craft and theory of public participation: a dialectica process. Journal of Risk Research 1999;2:55-71.

[63] Lynn FM. Public participation in risk management decisions: the right to define, the right to know, and the right to act. Risk - Issues in Health and Safety 1990;1:95-101.

[64] Robock A. 20 reasons why geoengineering may be a bad idea. Bulletin of the Atomic Scientists 2008;64:14-8. 59.

[65] Corner A, Pidgeon N, Parkhill K. Perceptions of geoengineering: public attitudes, stakeholder perspectives, and the challenge of 'upstream' engagement. WIREs Climate Change 2012;3:451-66. http://dx.doi.org/10.1002/wcc.176.

[66] Betz G. The case for climate engineering research: an analysis of the "arm the future" argument. Climatic Change 2012;111:473-85

[67] Gardiner SM. Is 'Arming the Future' with geoengineering really the lesser evil? Some doubts about the ethics of intentionally manipulating the climate system. In: Gardiner SM, Caney S, Jamieson D, Shue $\mathrm{H}$, editors. Climate ethics. Oxford: Oxford University Press; 2010. p. 284-314.

[68] Wintle BA, Runge MC, Bekessy SA. Allocating monitoring effort in the face of unknown unknowns. Ecology Letters 2010;13(11):132537. http://dx.doi.org/10.1111/j.1461-0248.2010.01514.x.

[69] Bunzl M. Researching geoengineering: should not or could not? Environmental Research Letters 2009;4(4):1-3. http://dx.doi.org $\underline{10.1088 / 1748-9326 / 4 / 4 / 045104}$ 